\title{
ABIN1 Determines Severity of Glomerulonephritis via Activation of Intrinsic Glomerular Inflammation
}

Erik A. Korte, ${ }^{*}$ Dawn J. Caster, ${ }^{* \dagger}$ Michelle T. Barati, ${ }^{*}$ Min Tan, ${ }^{*}$ Shirong Zheng, ${ }^{*}$ Celine C. Berthier, ${ }^{\ddagger}$ Frank C. Brosius, III, Mark B. Vieyra, ${ }^{*}$ Ryan M. Sheehan, ${ }^{*}$ Michele Kosiewicz, Marcin Wysoczynski, ${ }^{\star}$ Patrick M. Gaffney, ${ }^{\S}$ David J. Salant, Kenneth R. McLeish, ${ }^{\star \star}$ and David W. Powell*

\author{
From the Departments of Medicine* and Microbiology and Immunology, ${ }^{\S}$ University of Louisville, Louisville, Kentucky; the Robley Rex VA Medical Center, ${ }^{\dagger}$ \\ Louisville, Kentucky; the Department of Internal Medicine-Nephrology, ${ }^{\ddagger}$ University of Michigan, Ann Arbor, Michigan; the Arthritis and Clinical \\ Immunology Program and Clinical Pharmacology Research Program, "Oklahoma Medical Research Foundation, Oklahoma City, Oklahoma; and the \\ Department of Medicine," Boston University School of Medicine, Boston, Massachusetts
}

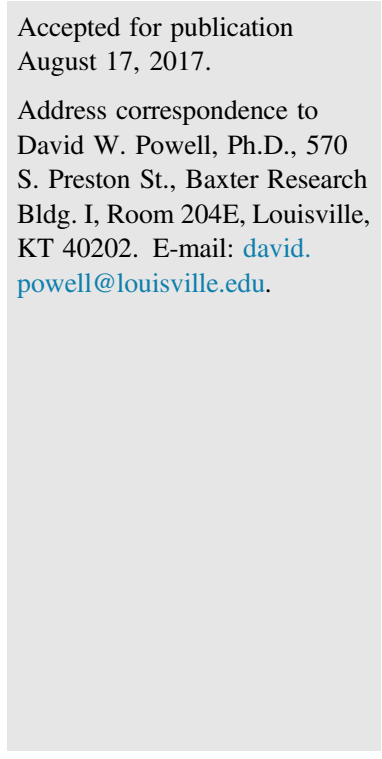

Accepted for publication August 17, 2017.

Address correspondence to David W. Powell, Ph.D., 570

S. Preston St., Baxter Research KT 40202. E-mail: david. powell@louisville.edu.

\begin{abstract}
Transcription factor NF- $\mathrm{KB}$ regulates expression of numerous genes that control inflammation and is activated in glomerular cells in glomerulonephritis (GN). We previously identified genetic variants for a $\mathrm{NF}-\mathrm{KB}$ regulatory, ubiquitin-binding protein ABIN1 as risk factors for GN in systemic autoimmunity. The goal was to define glomerular inflammatory events controlled by ABIN1 function in GN. Nephrotoxic serum nephritis was induced in wild-type (WT) and ubiquitin-binding deficient ABIN1[D485N] mice, and renal pathophysiology and glomerular inflammatory phenotypes were assessed. Proteinuria was also measured in ABIN1[D485N] mice transplanted with WT mouse bone marrow. Inflammatory activation of ABIN1 [D472N] (D485N homolog) cultured human-derived podocytes, and interaction with primary human neutrophils were also assessed. Disruption of ABIN1 function exacerbated proteinuria, podocyte injury, glomerular NF- $\kappa$ B activity, glomerular expression of inflammatory mediators, and glomerular recruitment and retention of neutrophils in antibody-mediated nephritis. Transplantation of WT bone marrow did not prevent the increased proteinuria in ABIN1[D845N] mice. Tumor necrosis factor-stimulated enhanced expression and secretion of NF- $\mathrm{KB}$-targeted proinflammatory mediators in ABIN1[D472N] cultured podocytes compared with WT cells. Supernatants from ABIN1[D472N] podocytes accelerated chemotaxis of human neutrophils, and ABIN1[D472N] podocytes displayed a greater susceptibility to injurious morphologic findings induced by neutrophil granule contents. These studies define a novel role for ABIN1 dysfunction and NF- $\mathrm{KB}$ in mediating $\mathrm{GN}$ through proinflammatory activation of podocytes. (Am J Pathol 2017, 187: 2799-2810; https://doi.org/10.1016/j.ajpath.2017.08.018)
\end{abstract}

The pathogenesis of various forms of glomerulonephritis (GN), including postinfectious GN, lupus nephritis, IgA nephropathy, anti-glomerular basement membrane (GBM) disease, and type I membranoproliferative GN, involves a complex interaction of molecules and cells. Glomerular immunoglobulin deposition and subsequent complement cascade activation stimulates mesangial cells and podocytes to produce proinflammatory cytokines, chemokines, vasoactive lipids, and procoagulants. ${ }^{1-3}$ Those inflammatory mediators recruit and activate leukocytes, including neutrophils, monocytes, and macrophages. ${ }^{4-9}$ Mediators of glomerular cell injury include reactive oxygen species, antimicrobial peptides and proteases, cytokines, the complement membrane attack complex, and direct cellcell-mediated injury.

Supported by the American Heart Association grant 14PRE19880002 (E.A.K.), NIH grants R01AR063124 (D.W.P. and P.M.G.) and R21AI103980 (D.W.P.), Juvenile Diabetes Research Foundation International grant 1-2011-588 (D.W.P.), and Department of Veterans Affairs Merit Review BX001838 (K.R.M.).

Disclosures: None declared.

K.R.M. and D.W.P. contributed equally as senior authors. 
Table 1 List of Renal Diseases and Characteristics Included in the Human Transcriptomic Study [European Renal cDNA Bank (ERCB) Cohort]

\begin{tabular}{|c|c|c|c|c|}
\hline Sample type & $\begin{array}{l}\text { No. of } \\
\text { samples }\end{array}$ & $\begin{array}{l}\text { eGFR MDRD, } \\
\text { means } \pm \mathrm{SD} \\
\left(\mathrm{mL} / \text { minute } / 1.73 \mathrm{~m}^{2}\right)\end{array}$ & $\begin{array}{l}\text { Age, means } \pm S D \\
\text { (years) }\end{array}$ & Sex \\
\hline Healthy living donor control & 31 & $107 \pm 30$ & $48.0 \pm 11.6$ & $16 \mathrm{M} / 15 \mathrm{~F}$ \\
\hline Diabetic nephropathy & 12 & $53 \pm 30$ & $54.3 \pm 11.0$ & $8 \mathrm{M} / 4 \mathrm{~F}$ \\
\hline Focal and segmental glomerulosclerosis & 24 & $75 \pm 34$ & $45.1 \pm 15.5$ & $12 \mathrm{M} / 12 \mathrm{~F}$ \\
\hline Hypertensive nephropathy & 15 & $41 \pm 24$ & $56.7 \pm 11.7$ & $12 \mathrm{M} / 3 \mathrm{~F}$ \\
\hline Membranous glomerulonephritis & 21 & $85 \pm 40$ & $53.3 \pm 17.9$ & $12 \mathrm{M} / 9 \mathrm{~F}$ \\
\hline Rapid progressive glomerulonephritis & 22 & $44 \pm 30$ & $58.3 \pm 14.2$ & $12 \mathrm{M} / 10 \mathrm{~F}$ \\
\hline Lupus nephritis & 32 & $64 \pm 29$ & $34.7 \pm 13.3$ & $7 \mathrm{M} / 25 \mathrm{~F}$ \\
\hline
\end{tabular}

Transcriptomic analyses from all the genes differentially regulated in the glomeruli of chronic kidney disease compared with living donor controls $(P<$ 0.05), generated using Genomatix Pathway System software version 2.8.1 (Genomatix Software, Munich, Germany).

F, female; M, male; eGFR, estimated glomerular filtration rate; MDRD, Modification of Diet in Renal Disease.

The transcription factor NF- $\kappa \mathrm{B}$ is activated in a number of inflammatory conditions, and both mesangial cells and podocytes demonstrate NF- $\kappa \mathrm{B}$ activation and cytokine production in response to proinflammatory mediators. ${ }^{10-12} \mathrm{NF}$ $\kappa \mathrm{B}$ signaling is upregulated in the glomeruli of patients with GN (Tables 1 and 2). Inhibition of NF- $\mathrm{B}$ signaling protects against development of disease, in part, through reduced expression of a number of cytokines that are transcriptional targets [eg, tumor necrosis factor (TNF)- $\alpha$, IL-1 $\beta$, macrophage chemoattractant protein [MCP]-1]. ${ }^{13-16}$ A20-binding inhibitor of NF- $\mathrm{KB}$ (ABIN1) is a ubiquitin-binding protein, which preferentially binds to lysine 63-linked and linear
(M1-linked) polyubiquitinated upstream regulatory components of NF- $\mathrm{B}$ and promotes their deubiquitination, which reduces $\mathrm{NF}-\kappa \mathrm{B}$ activation and expression of $\mathrm{NF}-\kappa \mathrm{B}$ target genes. ${ }^{17-19}$ Mutation of a conserved aspartic acid (D472 in human-derived cell lines) disrupts ABIN1 ubiquitin binding and inhibition of NF- $\kappa \mathrm{B} .{ }^{20}$ Mice that express this inactivating mutation in ABIN1 (D485N) spontaneously develop immune hyperactivation and severe immune complex-mediated GN starting at 3 to 4 months. ${ }^{20,21}$ Although immune cell activation was enhanced in ABIN1[D485N] mice, the effect of this mutation on the response of intrinsic glomerular cells to immune complex deposition was not addressed.

Table 2 Pathway Analysis Highlighted NF- $\kappa$ B Signaling in the Top Regulated Pathways

\begin{tabular}{|c|c|c|c|c|}
\hline Signal transduction pathways & $\begin{array}{l}\text { No. of } \\
\text { observed } \\
\text { genes }\end{array}$ & $\begin{array}{l}\text { No. of } \\
\text { expected } \\
\text { genes }\end{array}$ & $\begin{array}{l}\text { No. of } \\
\text { total } \\
\text { genes }\end{array}$ & $P$ value \\
\hline \multicolumn{5}{|l|}{$\begin{array}{l}\text { Top } 5 \text { signal transduction } \\
\text { pathways (canonical) }\end{array}$} \\
\hline Proteasome complex & 26 & 15 & 34 & $1.58 \times 10^{-04}$ \\
\hline $\begin{array}{l}\text { Induction of apoptosis through } \mathrm{dr} 3 \\
\text { and } \mathrm{dr} 4 / 5 \text { death receptors }\end{array}$ & 18 & 10 & 22 & $4.04 \times 10^{-04}$ \\
\hline Endogenous Toll-like receptor signaling & 15 & 8 & 18 & $9.03 \times 10^{-04}$ \\
\hline Antigen processing and presentation & 11 & 5 & 12 & $9.40 \times 10^{-04}$ \\
\hline \multicolumn{5}{|l|}{$\begin{array}{l}\text { Top } 10 \text { signal transduction pathways } \\
\text { (Genomatix literature mining) }\end{array}$} \\
\hline Toll-like receptor & 127 & 83 & 194 & $1.06 \times 10^{-10}$ \\
\hline Chemokine ( $\mathrm{C}-\mathrm{C}$ motif) ligand 2 & 74 & 50 & 117 & $5.93 \times 10^{-06}$ \\
\hline$N F-\kappa B$ & 204 & 164 & 384 & $2.00 \times 10^{-05}$ \\
\hline CD2 & 44 & 27 & 64 & $2.34 \times 10^{-05}$ \\
\hline Cell division cycle 2, $\mathrm{G} 1$ to $\mathrm{S}$ and $\mathrm{G} 2$ to $\mathrm{M}$ & 135 & 105 & 245 & $5.74 \times 10^{-05}$ \\
\hline Lymphocyte-specific protein tyrosine kinase & 62 & 43 & 100 & $7.95 \times 10^{-05}$ \\
\hline Aurora kinase & 86 & 63 & 147 & $8.15 \times 10^{-05}$ \\
\hline
\end{tabular}

Data were obtained from transcriptomic analyses of chronic kidney disease glomeruli compared to living donor controls (genes regulated with $P$ value $<0.05$ in chronic kidney disease compared with controls). 
To examine the role of glomerular cell ABIN1 function in GN, the present study compared the severity of acute antiGBM nephritis in wild-type (WT) and ABIN1[D485N] mice. A role for podocytes in this process was assessed with cell culture experiments.

\section{Materials and Methods}

\section{Animals}

Generation of ABIN1[D485N] mice has been previously described. ${ }^{20}$ Glomerular damage was induced using anti-GBM antibodies [nephrotoxic sera (NTS)] produced in sheep as previously described. ${ }^{22}$ Sterile NTS or control normal sera (NS) was injected into the tail vein of mice at $1.5 \mathrm{mg} / 25 \mathrm{~g}$ mouse body weight. TAT-SNAP-23 was produced as described previously. ${ }^{23}$ Administration of TAT-SNAP-23 was via tail vein injection at the time of NTS administration and 6 hours after administration at a concentration of $0.05 \mathrm{mg} / \mathrm{kg}$ body weight. All bone marrow transplantations were performed in 6-week-old mice. Ten WT mice received WT bone marrow, and 10 received $\mathrm{ABIN} 1[\mathrm{D} 485 \mathrm{~N}]$ bone marrow. Likewise, 10 ABIN1[D485N] mice received WT bone marrow, and 10 received ABIN1[D485N] bone marrow. Engraftment was confirmed using leukocytes isolated from whole blood. The ABIN1[D485N] mouse model was a gift from Dr. Philip Cohen and Dr. Sambit Nanda (University of Dundee, Dundee, Scotland). All animal studies were approved by the Institutional Animal Care and Use Committee of the University of Louisville (Louisville, KY).

\section{Urine Albumin:Creatinine}

Spot urine samples were captured by massaging the bladder and collected in sterile microcentrifuge tubes. Urine was centrifuged at $5000 \times g$ for 5 minutes, and then standard sandwich enzyme-linked immunosorbent assay (ELISA) was performed in triplicate according to the manufacturer's protocol for mouse albumin (Bethyl Laboratories, Montgomery, TX) and a kinetic Jaffe method for creatinine (Thermo Fisher Scientific, Waltham, MA). The ratio of albumin and creatinine was calculated for each sample.

\section{Kidney Pathologic Findings}

Glomerular damage was assessed from periodic acidSchiff-stained kidneys by blinded semiquantitative scoring of cellularity (proliferation) and mesangial matrix expansion on a 0 (normal), $1+$ (mild abnormality), $2+$ (moderate abnormality), and $3+$ (severe abnormality) scale by two nephrologists (D.J.C. and K.R.M.). Immunohistochemistry (IHC) analysis was performed with a previously described method. ${ }^{24}$ Primary antibodies dilutions were applied at 1:200 for WT-1 (Santa Cruz Biotechnology, Dallas, TX) and CD45 (Angio-Proteomie, Boston, MA), NF-кB (p65) (Santa Cruz Biotechnology) and 1:50 for myeloperoxidase (MPO)
(AbCam, Cambridge, MA) and fluorescein isothiocyanate conjugated anti-C3 (PA1-29718; Thermo Fisher Scientific). Biotinylated secondary antibodies (1:200; Vector Labs, Burlingame, CA) were used for detection. CD45-, MPO-, WT-1-, or NF- $\kappa$ B (p65)-positive glomerular cells were counted manually with light microscopy. For quantification of C3 immunostaining in the glomerular tuft, glomeruli were outlined to exclude Bowman's capsule. Total sum of fluorescein isothiocyanate fluorescence intensity within the outlined region (integration value) was measured using FV-10 ASW software version 2.1 (Olympus, Center Valley, PA). Values for multiple images per sample were averaged.

\section{Actin Labeling and Confocal Microscopy}

Confocal microscopy images were obtained as previously described. ${ }^{25}$ Briefly, 35-mm collagen-coated glass bottom dishes (MatTek, Ashland, MA) were seeded with podocytes and allowed to mature at $37^{\circ} \mathrm{C}$ for 10 days. Cells were serum starved with $0.5 \%$ fetal bovine serum medium 24 hours before stimulant was added. After stimulation, cells were rinsed three times with phosphate-buffered saline (PBS) that contained calcium and magnesium and fixed in 3.7\% paraformaldehyde in PBS for 10 minutes, followed by permeabilization with $0.025 \% \mathrm{NP}-40$ in PBS for 15 minutes and washing. Cells were blocked in 5\% bovine serum albumin in PBS for 30 minutes before addition of $200 \mu \mathrm{L}$ (3 units) of rhodamine-phalloidin (Thermo Fisher Scientific) for 30 minutes. After another wash, $300 \mathrm{nM}$ DAPI was incubated for 5 minutes and rinsed three times with PBS, mounted using Vectashield Antifade Mounting Medium for Fluorescence (Vector Labs). Images were acquired using an Olympus Fluoview FV-1000 confocal coupled to an Olympus 1X81 inverted microscope and FV-10 ASW software and features quantified with FibrilTool. ${ }^{26}$

\section{Real-Time Quantitative PCR}

Cells or purified glomeruli were washed in ice-cold PBS, and RNA was extracted immediately using the Aurum Total RNA Mini kit (BioRad, Hercules, CA), quantified on a Nanodrop2000 (Thermo Fisher Scientific) and converted into cDNA using iScript RT Supermix (BioRad). A custom gene expression array was developed in house and produced by BioRad on 384-well plates, and samples were run in duplicate, normalized to glyceraldehyde-3-phosphate dehydrogenase expression levels and reported as fold change using the $\Delta \Delta \mathrm{Ct}$ method. For single-target real-time quantitative PCR, custom primers were developed and optimized using Primer-BLAST (National Center for Biotechnology Information, Bethesda, MD). Cultured human podocytes were assessed for NF- $\kappa \mathrm{B}$ target gene expression changes using the SA Biosciences NF- $\kappa$ B Signaling Target Array (Qiagen, Redwood City, CA). Conversion to cDNA was identical to the custom array, and all samples were run in triplicate in at least three individual experiments and normalized to glyceraldehyde-3-phosphate dehydrogenase. 


\section{Cultured Podocytes}

We used a commonly used human-derived podocyte cell line and culturing protocol described by Mundel and colleagues. ${ }^{27} \mathrm{We}$ produced lentivirus capable of inducing expression of ABIN1 WT or ABIN1[D472N] at a multiplicity of infection of 1 to 10 with polybrene (SigmaAldrich, St. Louis, MO) to achieve equal expression of WT and ABIN1[D472N] in each cell line. All experiments were completed in triplicate on cells grown to $70 \%$ confluence at $33^{\circ} \mathrm{C}$ then incubated for at least 10 days at $37^{\circ} \mathrm{C}$.

\section{Neutrophil Chemotaxis}

Primary neutrophils were obtained from the blood of healthy donors and isolated via the Percoll gradient method. The institutional review board of the University of Louisville approved the use of human donors who provided informed consent. Neutrophils were resuspended at $5 \times 10^{4}$ in Krebs buffer, and $100 \mu \mathrm{L}$ of suspended cells were allowed to undergo a 30-minute chemotaxis per manufacturer guidelines into 6.6$\mathrm{mm}$ diameter and $3-\mu \mathrm{mol} / \mathrm{L}$ pore size Transwell Permeable Supports (Corning Inc., Corning, NY) using a 1:600 dilution of podocyte culture supernatant in sterile, endotoxin-free Krebs buffer. The Hema 3 protocol (Thermo Fisher Scientific) was used to fix and stain the membranes.

\section{ELISA}

Levels of MCP-1, IL-8, and TNF- $\alpha$ were determined using the BioLegend (San Diego, CA) ELISA Max Deluxe kits per the manufacturer protocol. To allow secretome samples to be used with primary neutrophils, samples were stimulated for 6 hours with TNF- $\alpha$ followed by 3 washes in sterile, endotoxin-free Krebs buffer, followed by a 6 hours collection in $10 \mathrm{~mL}$ of Krebs buffer per $10-\mathrm{cm}$ dish at $70 \%$ confluence. This stimulation and wash regimen was determined to be optimal for the cytokines of interest, and no detectable TNF- $\alpha$ remained after the three wash steps $(<2 \mathrm{pg} / \mathrm{mL})$.

\section{Statistical Analysis}

Statistical analysis was completed as described in the figure legends. GraphPad Prism software version 5.01 (GraphPad Software, Inc., La Jolla, CA) was used for statistical analyses, and accepted statistical significance is defined within the figure legends.

\section{Results}

ABIN1[D485N] Mice Exhibit Enhanced Proteinuria and Glomerular Cell Injury

We previously reported that ABIN1[D485N] knock-in mice spontaneously develop severe, immune complex GN beginning at 3 to 4 months of age that is associated with dysregulation of the immune system. ${ }^{21}$ The ABIN1[D485N] mutant lacks polyubiquitin-binding activity and is globally expressed in these knock-in mice. Thus, to determine whether development or severity of GN is mediated by loss of intrinsic glomerular ABIN1 function, GN was induced exogenously in ABIN1 [D485N] mice by administration of NTS at an age before spontaneous development of GN (approximately 6 weeks old). The NTS contains antibody against GBM components and is a well-documented model for induction of GN within 24 hours, devoid of systemic immune contribution. ${ }^{28,29}$ Figure $1 \mathrm{~A}$ shows urine albumin:creatinine (UAC) ratios from ABIN1[D485N] and WT mice obtained at 0 and 24 hours after tail vein injection of anti-GBM containing NTS. Basal UAC ratios of WT and ABIN1[D485N] mice were not different, and administration of control, mouse NS immunoglobulin did not increase the 24-hour UAC ratio above unstimulated levels in WT or ABIN1[D485N] mice. Both WT and ABIN1[D485N] mice had a significant increase in UAC ratios 24 hours after NTS administration, but the ninefold increase in UAC in ABIN1[D485N] mice was significantly greater than increased UAC in WT mice. A blinded semiquantitative glomerular histologic scoring evaluation was performed to assess the amount of mesangial matrix and mesangial cellularity or proliferation (D.J.C. and K.R.M.). Figure 1B shows that mesangial cell proliferation was slightly elevated in WT and ABIN1 mice treated with NTS versus NS control, but no substantial differences in mesangial cell proliferation or mesangial matrix expansion between WT and ABIN1 [D485N] mice treated with NTS or NS control. However, mesangial expansion was more prevalent in ABIN[D485N] mice treat with NTS. Transmission electron microscopy revealed more diffuse foot process effacement in NTS-treated ABIN1[D485N] mice compared with NTS-treated WT mice (Figure 1C). Enhanced podocyte injury in NTS-treated ABIN1 [D485N] mice was also supported by lower numbers of WT-1 (podocyte marker) positive glomerular cells compared with that of NTS-treated WT mice (Figure 1D).

To separate the effects of ABIN1[D485N] on systemic immune activation and intrinsic renal cells, glomerular C3 deposition was analyzed and nephritis was induced after bone marrow transplant. Figure $1, \mathrm{E}$ and $\mathrm{F}$ shows that glomerular C3 deposition was slightly elevated in WT and ABIN1[D485N] mice treated with NTS compared with NStreated controls, but the difference was not statistically significant, and there was no apparent difference between NTS-treated WT and ABIN1[D485N] mice. Figure 1G shows that UAC at 24 hours did not differ in WT mice receiving transplants with $\mathrm{WT}$ or ABIN1[D485N] mouse bone marrow. ABIN1[D485N] mice had significantly greater UAC ratios than WT mice independently of transplantation with WT or ABIN1[D485N] bone marrow. Those results suggest that the ABIN1 mutation in glomerular cells, not immune cells, determines the extent of glomerular injury leading to proteinuria. This postulate is further supported by development of spontaneous proteinuria in ABIN1[D485N] mice receiving transplants with WT bone marrow (Figure 1H). 
A

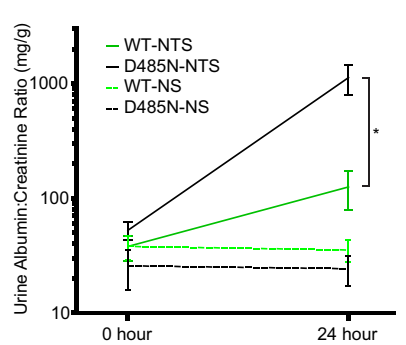

C

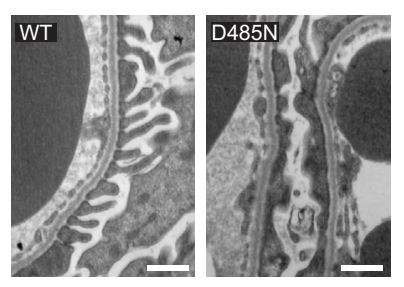

E

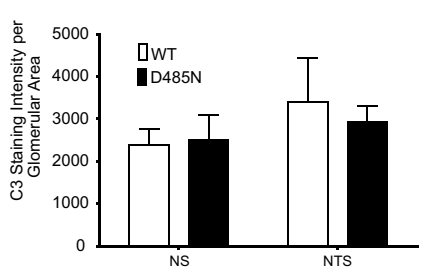

G

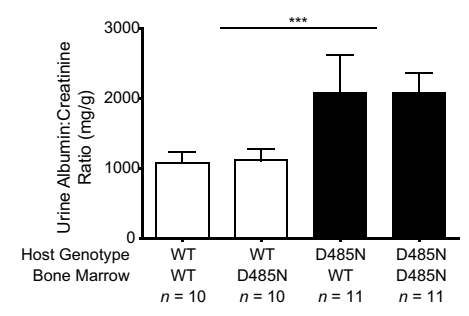

B
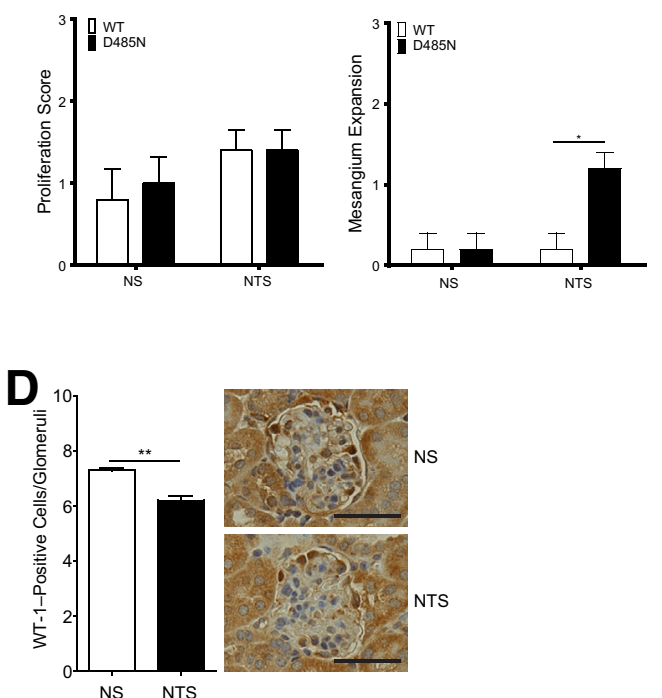

$\mathbf{F}$
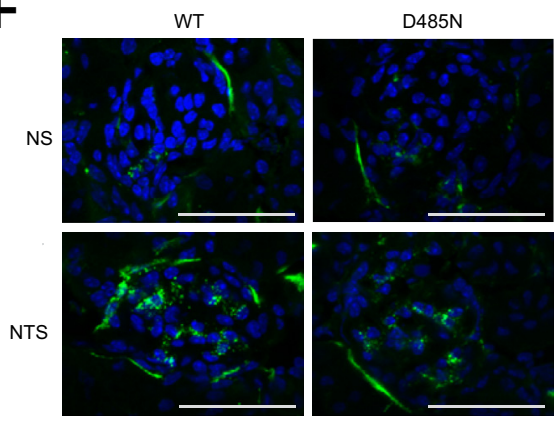

H

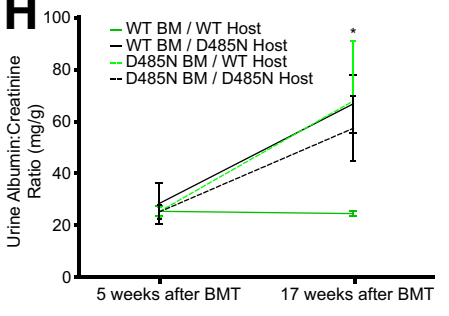

Figure 1 ABIN1[D485N] mice have enhanced proteinuria after nephrotoxic sera (NTS) administration. A: Anti-glomerular basement membrane that contained NTS administered to mice at 6 weeks of age produces significantly different levels of proteinuria, with ABIN1[D485N] animals exhibiting nine times the level of urine albumin 24 hours after NTS administration. Normal serum (NS) served as a control and did not induce proteinuria. B: Blinded histologic scoring of periodic acid-Schiff-stained sections had only minor changes 24 hours after injection (D.J.C. and K.R.M.). All conditions were statistically identical to ABIN1 wild-type (WT) animals given control serum (NS), with the exception of elevation of matrix expansion in ABIN1 [D485N] mice treated with NTS. C: Transmission electron microscopy of ABIN1 WT glomeruli 24 hours after NTS revealed minor foot process effacement. ABIN1[D485N] mice had massive foot process effacement at 24 hours. Representative images highlight this discrepancy. Endothelial cell changes and basement membrane thickening were not widespread. D: NTS-treated ABIN1[D485N] mice had a significant lower number of WT-1 (podocyte marker)-positive glomerular cells compared with that of WT mice. E: Glomerular C3 deposition was assessed using immunofluorescent microscopy by normalizing the C3 staining intensity to the glomerular area with no significant differences noted. F: Representative images of E. G: Bone marrow transplant (BMT) using WT hosts and WT or ABIN1[D485N] bone marrow at 6 weeks of age produced no change in proteinuria at 13 weeks of age 24 hours after NTS. Likewise, ABIN1 [D485N] hosts did not respond differently because of immune genotypes; however, the host genotype was related to a significant change in proteinuria severity after NTS administration. $\mathbf{H}$ : In an independent cohort with the same groups as in $\mathbf{G}$, mice received transplants at 6 weeks of age, and spontaneous urine albumin:creatinine ratio was measured at 5 and 17 weeks after BMT. Spontaneous proteinuria developed at 17 weeks after BMT in all the groups, except WT mice receiving WT BMT. Statistical analysis of the mean of replicates used 1-way analysis of variance with Bonferroni's post hoc in $\mathbf{A}$ and $\mathbf{H}$; 2-way analysis of variance with Bonferroni's post hoc in $\mathbf{B}, \mathbf{E}$, and $\mathbf{G}$; and $t$-test in D. Error bars indicate SEM. $n=9$ for WT and $n=12$ ABIN1[D485N] in the NTS group and $n=10$ for WT and $n=11$ ABIN1 [D485N] in the NS group (A); $n=5$ per condition with 30 glomeruli assessed per sample (B); $n=4$ per condition (E); $n=10$ each (G); $n=3$ each $(\mathbf{H}) .{ }^{*} P<0.05,{ }^{*} P<0.01$, and $* * * P<0.001$ versus controls. Scale bars: $500 \mathrm{~nm}(\mathbf{C})$; $50 \mu \mathrm{m}$ (D and F).

\section{ABIN1[D485N] Mice Exhibit Enhanced Glomerular Inflammation}

To define glomerular inflammatory events controlled by intrinsic ABIN1 function, glomerular cell nuclear expression of the active p65 NF- $\kappa \mathrm{B}$ subunit was assessed by IHC at 2 hours after NTS, measuring production of NF- $\mathrm{BB}$ inflammatory target genes by glomerular cells with custom real-time quantitative PCR analysis 24 hours after NTS, and counting the number of CD45-positive and MPO-positive leukocytes in glomeruli by IHC at 2 and 24 hours after NTS administration. Figure 2, A and B shows that there were significantly more p65-positive nuclei in glomeruli 2 hours after NTS administration in ABIN1[D485N] mice compared with WT. The control groups treated with NS also had constitutive glomerular NF- $\kappa$ B activation in ABIN1[D485N] mice. Genes 


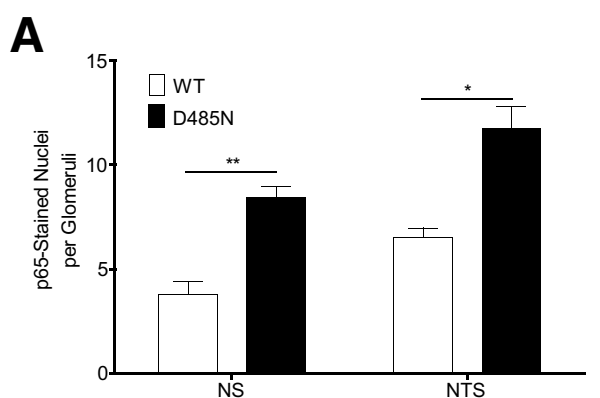

C

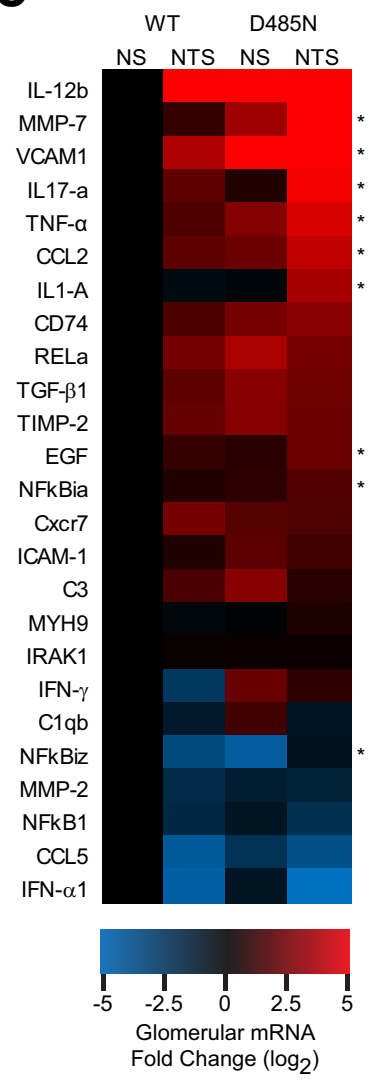

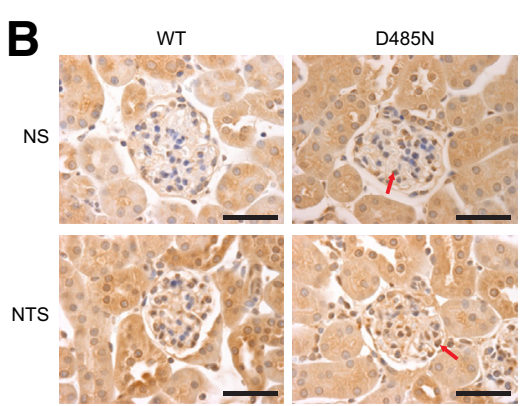

D

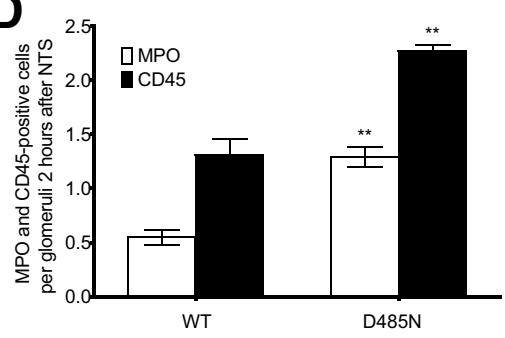

E
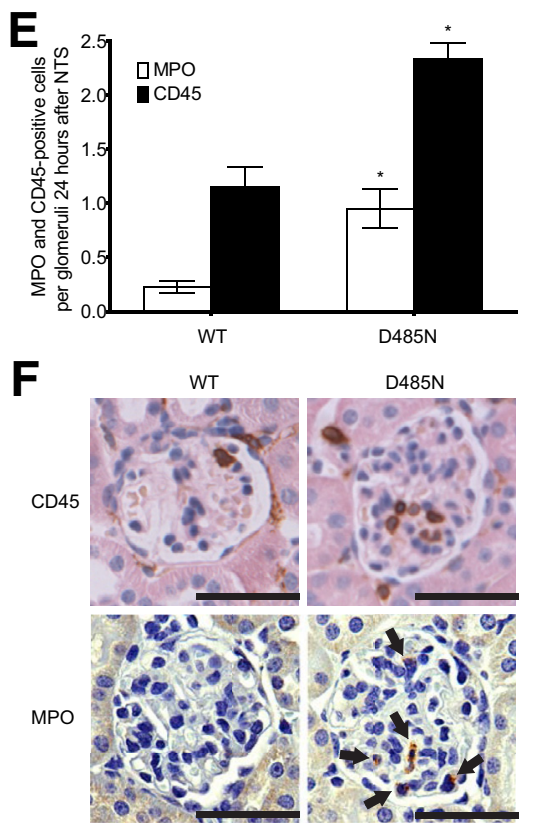

Figure 2 ABIN1[D485N] mice have enhanced glomerular inflammation after nephrotoxic sera (NTS) administration. A: Immunohistochemistry (IHC) analysis was used to compare nuclear expression of the NF- $\kappa B$ p 65 subunit (indicative of $N F-\kappa B$ activation) within the glomerulus at 2 hours after NTS or normal serum (NS) control administration in wild-type (WT) and ABIN1 [D485N] mice. B: Representative images (arrows indicate examples of positive nuclear p65 expression). C: Isolated glomeruli from WT or ABIN1[D485N] kidneys revealed marked transcriptional changes in a number of proinflammatory cytokines, chemokines, and adhesion molecules. IHC was used to reveal increased levels of CD45-positive and myeloperoxidase (MPO)positive cells within the glomerulus at 2 hours (D) and 24 hours (E) after NTS. F: Representative images of glomeruli 24 hours after NTS (arrows indicate location of granular MPO staining). Error bars represent SEM, and the $t$-test was used to compare values between 2 groups. $n=3$ per condition with 10 glomeruli counted per sample (A); $n=4$ per condition (C); $n=5$ per condition with 30 glomeruli counted per sample (D and $\mathbf{E}$ ). ${ }^{*} P<0.05,{ }^{* *} P<0.01$ versus controls. Scale bar $=50 \mu \mathrm{m}$ (B and F). CCL, chemokine (C-C motif) ligand; EGF, epidermal growth factor; ICAM1, intercellular adhesion molecule-1; IFN, interferon; MMP-7, matrix metalloproteinase-7; MYH9, myosin heavy chain-9; RELa, NF-kB p65 subunit; TGF- $\beta 1$, transforming growth factor- $\beta 1$; TNF- $\alpha$, tumor necrosis factor- $\alpha$; VCAM- 1 , vascular cell adhesion molecule-1. in the real-time quantitative PCR analysis included adhesion molecules (vascular cell adhesion molecule-1, intercellular adhesion molecule 1), profibrotic and proinflammatory mediators (transforming growth factor- $\beta 1, \mathrm{C} 1 \mathrm{qB}, \mathrm{C} 3, \mathrm{CD} 74$, epidermal growth factor), interferons (IFNs) (IFN- $\alpha 1$, IFN$\gamma$ ), chemokines and cytokines (MCP-1, CCL5, CXCR7, TNF- $\alpha$, IL-1 $\alpha$, IL-12b, IL-17a), cytoskeletal and matrix proteins [myosin heavy chain-9, matrix metalloproteinase (MMP)-2, MMP-7, tissue inhibitor of metalloproteinase 2], and NF- $\kappa \mathrm{B}$ pathway proteins (NF-kB p65 subunit, NF- $\kappa \mathrm{Bi} \alpha$,

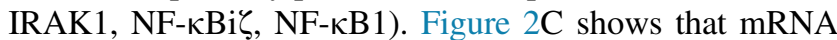
expression of a number of proinflammatory cytokine and adhesion proteins was significantly increased in ABIN1 [D485N] mouse glomeruli 24 hours after NTS administration. Compared with WT mice, glomeruli isolated from
ABIN1[D485N] mice had a 40-fold increase in mRNA for MMP-7, a 13-fold increase in IL-1 $\alpha$, a sixfold increase in TNF- $\alpha$, a threefold increase in vascular cell adhesion molecule 1, and twofold increases for IL-17 $\alpha$, CCL2/MCP-1, and epidermal growth factor. Constitutive enhancement for these genes was also observed in NS control-treated ABIN1 [D485N] mice. CD45 is expressed on all leukocytes, whereas MPO is highly expressed in neutrophil azurophilic granules, modestly expressed in monocyte lysosomes, and lost from tissue macrophages. ${ }^{30}$ ABIN1[D485N] mouse glomeruli had a significantly greater number of CD45-positive cells at 2 and 24 hours after NTS compared with WT mice (Figure 2, D and E). ABIN1[D485N] mice also had a significantly increased number of MPO-positive cells per glomerulus at 2 hours compared with WT mice (Figure 2D). At 24 hours, WT mice 

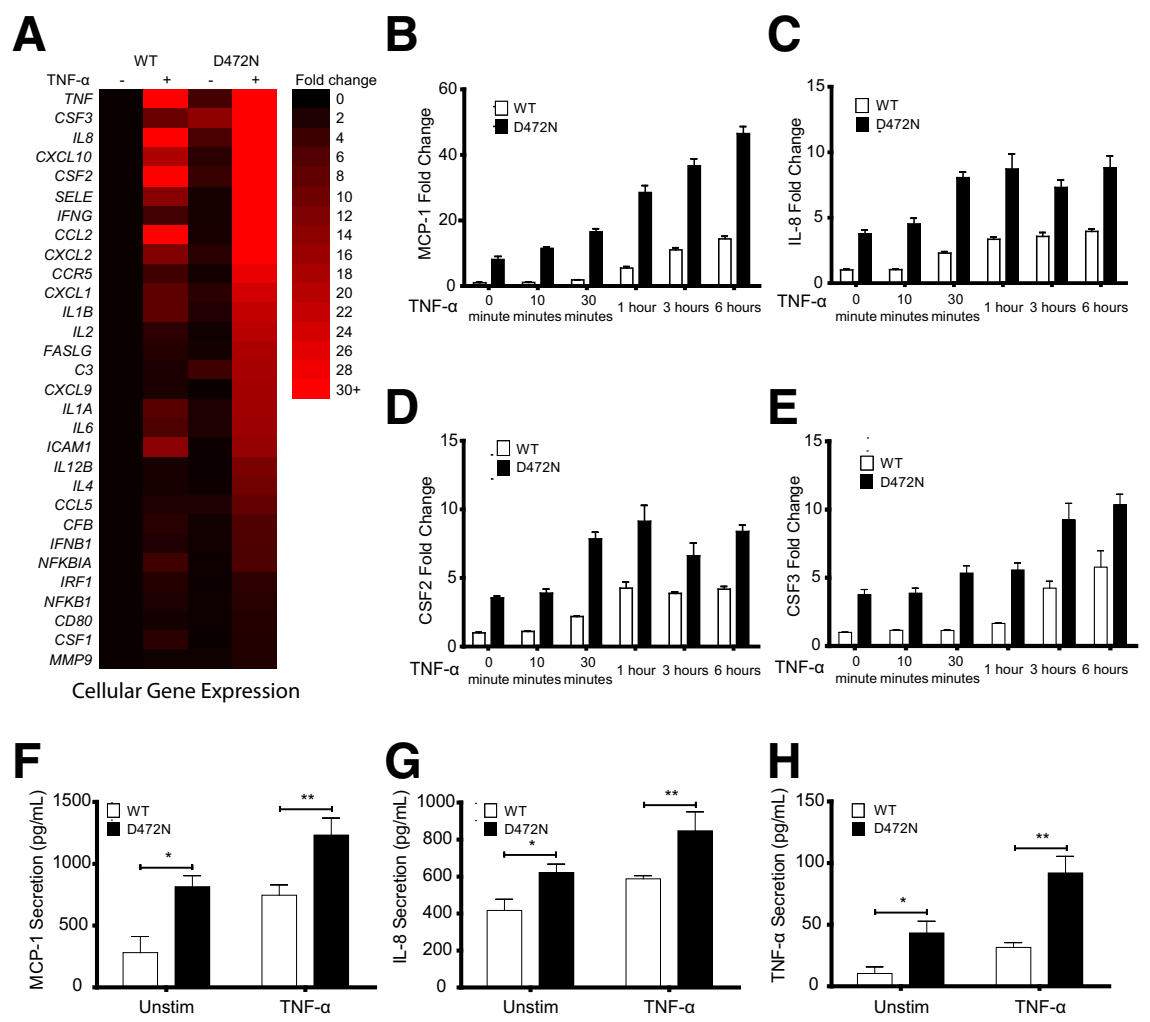

Figure 3 Cultured podocytes produce proinflammatory cytokines and chemokines and dysfunctional ABIN1 is associated with higher rates of expression. A: Real-time quantitative PCR array revealed transcriptional changes similar to what was reported in isolated glomeruli after a 3-hour stimulation by tumor necrosis factor (TNF)- $\alpha$. Notably, proinflammatory cytokines and chemokines were expressed at higher levels in ABIN1 [D472N] expressing podocytes with or without stimulation (unstim). B-E: Validation of four cytokines noted in the array revealed significant increases in expression using single-target real-time quantitative PCR with stimulation times ranging from 0 to 6 hours. Expression of these targets was 4to 10-fold higher even at basal levels in cells expressing ABIN1[D472N]. Statistical analysis used 2-way analysis of variance with Bonferroni post hoc analysis, and all paired time points were significant to at least $P<0.01$. $\mathbf{F}-\mathbf{H}$ : Quantification of secreted proteins by enzyme-linked immunosorbent assay revealed that the differences in transcript corresponded to increased secretion of cytokines and chemokines into the cell culture supernatant. The $t$-test compared values between two groups. $n=3$ per condition $(\mathbf{A}, \mathbf{F}-\mathbf{H}) ; n=4$ independent assays per condition (B-E). ${ }^{*} P<0.05$, ${ }^{* *} P<0.01$ versus controls. MCP-1, macrophage chemoattractant protein-1. had a reduction in MPO-positive cells per glomerulus compared with 2 hours, whereas ABIN1[D485N] mice continued to have a significantly increased number of MPOpositive cells compared with WT mice (Figure 2, E and F). Previous reports indicate that NTS induces glomerular leukocyte accumulation by 2 hours and is essentially absent by 6 hours in WT mice. ${ }^{28,29}$ These results suggest that ABIN1 function in intrinsic glomerular cells regulates production of specific cytokines and chemokines required for leukocyte recruitment through control of NF- $\kappa \mathrm{B}$.

Loss of ABIN1 Ubiquitin-Binding Function in Cultured Podocytes Results in Excess Production and Secretion of NF- $\kappa \mathrm{B}$-Targeted Proinflammatory Mediators

To determine whether ABIN1 regulates NF- $\mathrm{BB}$ activation and proinflammatory responses in podocytes, NF- $\mathrm{B}$ - targeted gene array analysis was conducted after 3-hour incubation with the proinflammatory cytokine TNF- $\alpha$ in WT and ABIN1[D472N] (D485N homolog) human-derived cultured podocytes. The array assessed NF- $\mathrm{KB}$ target genes categorized as chemokines or cytokines $(n=27)$, inflammatory markers $(n=33)$, or immune mediators $(n=30)$. Figure $3 \mathrm{~A}$ shows that NF- $\mathrm{KB}$ target gene expression exhibited mild differences between WT and ABIN1 [D472N] expressing podocytes in the absence of TNF- $\alpha$. After incubation with TNF- $\alpha$, however, expression of many of the NF$\kappa \mathrm{B}$ target genes was increased in ABIN1[D472N] podocytes. TNF- $\alpha$-mediated increased gene expression of chemoattractants MCP-1 (CCL2), IL-8, CSF2 (GM-CSF), and CSF3 (G-CSF) was confirmed using single-target real-time quantitative PCR (Figure 3, B-E). Those target genes revealed a 4- to 10-fold increased expression in ABIN1[D472N] podocytes without exogenous stimulation. After incubation with TNF- $\alpha$ for up to 6 hours, the increased gene expression remained several-fold greater in ABIN1[D472N] podocytes. To confirm that increased gene expression resulted in increased protein secretion, podocyte supernatants were collected without contamination by fetal bovine serum or exogenous TNF- $\alpha$, as outlined in Materials and Methods. ELISA for MCP-1, IL-8, and TNF- $\alpha$ confirmed that increased secretion of these NF$\kappa \mathrm{B}-$-regulated proinflammatory proteins was associated with increased gene expression in ABIN1[D472N] podocytes (Figure 3, F-H). Note that enhanced constitutive and TNF$\alpha$-stimulated responses were observed with ABIN1[D472N] cells. Considered with the results from ABIN1[D485N] mice, these findings suggest that impaired ABIN1 function in podocytes contributes to the development of GN by mediating enhanced production of NF- $\mathrm{KB}$-targeted cytokines and chemokines required for leukocyte recruitment and retention.

\section{Supernatant from ABIN1[D472N] Cultured Podocytes Activate Neutrophil Chemotaxis and ABIN1[D472N] Podocytes Are More Susceptible to Morphologic Injury Provoked by Neutrophil Granule Products}

To determine whether ABIN1 dysfunction in podocytes was a potential mechanism for enhanced leukocyte recruitment into the glomerulus, the ability of supernatants from WT and ABIN1 [D472N] human-derived cultured podocytes to stimulate chemotaxis of primary human neutrophils was determined. 
A

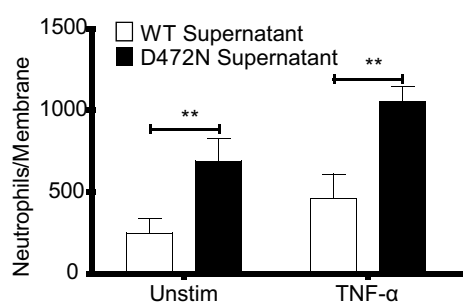

D

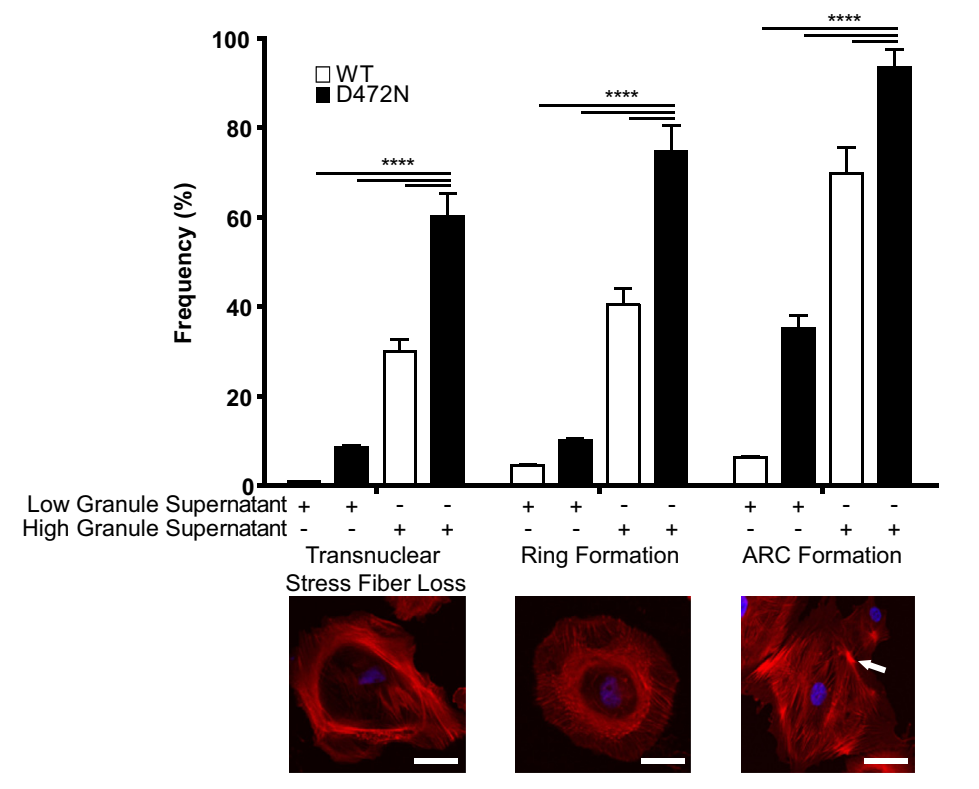

C

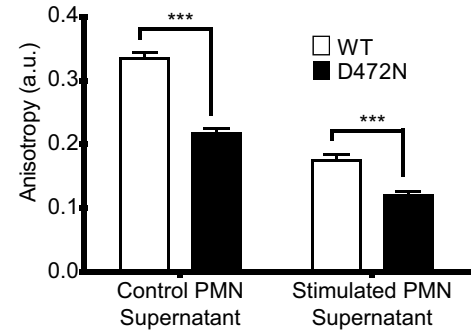

E
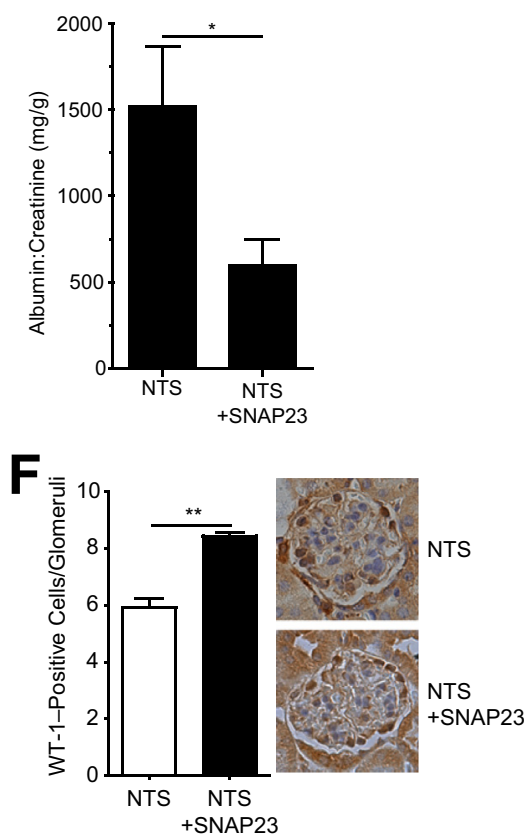

G
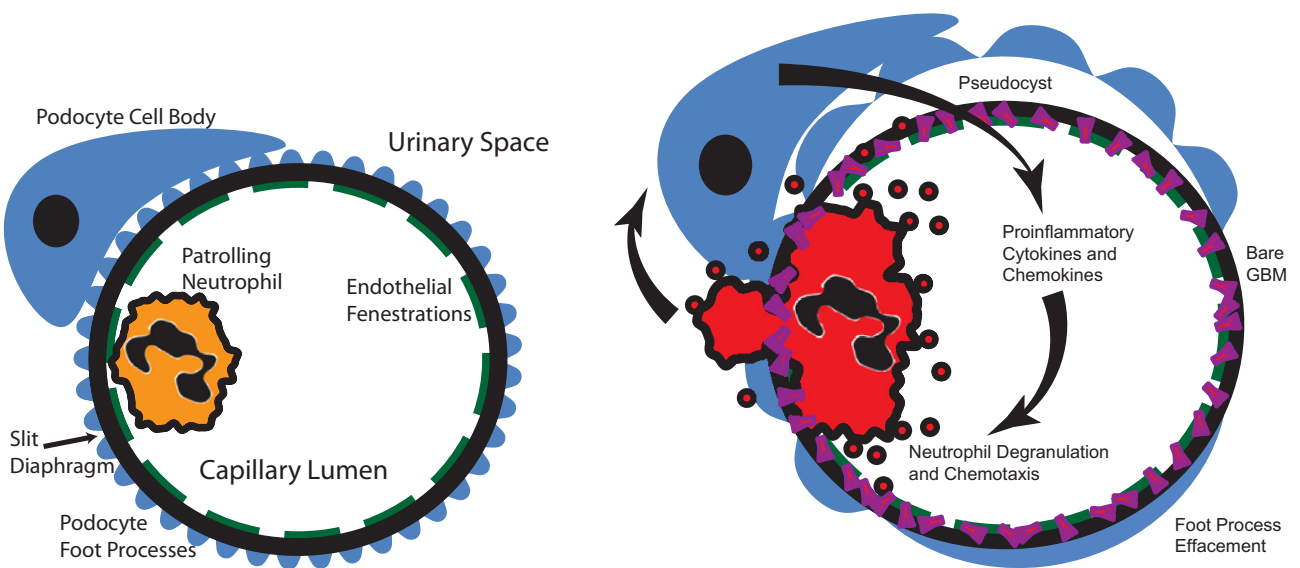

Nephrotoxic Antibodies and

Healthy Glomerular Capillary ABIN1 polymorphisms NF-kB Activation 
Supernatants from podocytes expressing ABIN1[D472N] stimulated a significant threefold increase in neutrophil chemotaxis compared with WT ABIN1 podocyte supernatants, with or without TNF- $\alpha$ stimulation (Figure 4A). To determine whether neutrophils in turn mediate podocyte injury, the effect of granule contents released from human neutrophils on cytoskeletal morphologic findings of cultured podocytes was examined. Podocytes were cultured for 24 hours with supernatants from primary human neutrophils stimulated to undergo degranulation with TNF- $\alpha$ and formyl-methionyl-leucyl phenylalanine or unstimulated neutrophils (control), and podocyte actin stress fibers were visualized using rhodaminephalloidin staining. Both WT and ABIN1[D472N] podocytes had typical healthy actin stress fiber structure after 24-hour incubation with control neutrophil supernatant, including the presence of long stress fibers that extended at least half the length of the cell and crossed the nucleus, with a primarily unidirectional distribution (Figure 4B). Anisotropy is a measurement of the angularity of F-actin stress fibers. FibrilTool was used to measure anisotropy by using rotational statistics to quantify changes to F-actin organization of raw images to avoid reprocessing bias. ${ }^{26}$ Figure $4 \mathrm{C}$ shows that anisotropy was significantly reduced in ABIN1[D472N] podocytes compared with WT, whether cultured with control or stimulated neutrophil supernatants. Stimulated neutrophil supernatant induced a significant loss of stress fiber anisotropy compared with control supernatant in both WT and ABIN1[D472N] podocytes. Each cell assessed by FibrilTool was also examined for three additional features of podocyte morphologic alteration: transnuclear stress fiber loss, ring formation, and actin-rich center formation (Figure 4D). ${ }^{31-35}$ All three of these features were found to be significantly increased in ABIN1[D472N] podocytes cultured with stimulated neutrophil supernatant compared with WT podocytes.

This apparent susceptibility of ABIN1[D472N] podocyte to morphologic disruption induced by products of neutrophil granules suggested that neutrophil degranulation participates in the enhanced NTS-induced podocyte injury and proteinuria in ABIN1[D485N] mice. To test this postulate, we used a unique fusion protein, TAT-SNAP-23, to inhibit neutrophil degranulation in vivo. ${ }^{23,36-38}$ ABIN1[D485N] mice treated with TAT-SNAP-23 at the time of NTS administration and 6 hours later had a significant reduction in proteinuria at 24 hours (Figure 4E). TAT-SNAP-23 treatment also increased the number of WT-1-stained cells per glomeruli in ABIN1[D485N] mice (Figure 4F). These results suggest that podocytes with impaired ABIN1 are prone to injury by neutrophil granule proteins.

\section{Discussion}

GN is typically initiated by glomerular deposition of immunoglobulin, leading to leukocyte recruitment by proinflammatory products secreted by injured intrinsic glomerular cells and chemotactic complement fragments. ${ }^{1-3}$ The current study found that genetic regulation of the intrinsic glomerular milieu is an additional factor that determines susceptibility and severity of glomerular injury. ABIN1 has emerged as a novel physiologic inhibitor of NF- $\kappa \mathrm{B}$ and a genetic factor in autoimmunity and $\mathrm{GN}^{20,21,39,40}$ Our study found that transgenic disruption of glomerular ABIN1 polyubiquitin-binding activity (D485N) resulted in enhanced anti-GBM antibody-mediated injury, resulting in podocyte dysfunction and proteinuria. That injury was associated with increased glomerular NF- $\mathrm{BB}$ activation and expression of NF- $\kappa \mathrm{B}-$ dependent proinflammatory cytokines and chemokines and increased and prolonged glomerular recruitment of neutrophils. Our data also suggest that neutrophil granule release is an important contributor to podocyte injury. Thus, we identified ABIN1 as a novel intrinsic regulator of the glomerular inflammation that contributes to the pathogenesis of GN. This postulate is supported by increased proteinuria with NTS administration in ABIN1[D485N] mice transplanted with WT bone marrow and spontaneous proteinuria observed at 6 months in ABIN1[D485N] mice transplanted with WT bone marrow at 6 weeks of age.

Negative regulation of NF- $\mathrm{KB}$ and its targeted production of hundreds of cytokines and chemokines provide an important

Figure 4 Podocytes secrete a milieu that can activate neutrophils, and neutrophils produce granules, which initiate remodeling of the podocyte cytoskeleton. A: Chemotaxis of primary human donor neutrophils into synthetic membranes was induced by podocyte cell culture supernatant over control cell culture media, and stimulation of the podocytes before washing and collection of their media resulted in greater rates of chemotaxis. Furthermore, podocytes expressing ABIN1 [D472N] induced twice the rates of chemotaxis as ABIN1 wild type (WT). B: Neutrophil granules induced major cytoskeletal remodeling of cultured podocytes. Representative images of rhodamine-phalloidin-stained F-actin show parallel stress fibers in podocytes exposed to supernatant from unstimulated (unstim) neutrophils, but loss of length and orientation of these stress fibers on 24-hour exposure to supernatant from tumor necrosis factor (TNF)- $\alpha-$ formyl-methionylleucyl phenylalanine-stimulated neutrophils. C: The loss of stress fiber orientation was quantified using Fibriltool as described in the Materials and Methods. The anisotropy of F-actin was significantly reduced by exposure to neutrophil granules and in podocytes that expressed ABIN1[D472N]. D: 0ther commonly cited morphologic changes assessed were loss of transnuclear stress fibers, ring formation, and actin-rich center (ARC) formation. Representative images for each are given (white arrow indicates ARC). E: ABIN1[D485N] mice treated with an inhibitor of neutrophil degranulation (TAT-SNAP-23) at the time of nephrotoxic serum (NTS) administration and 6 hours later had a significant reduction in proteinuria at 24 hours. F: TAT-SNAP-23 treatment increased the number of WT-1-stained cells per glomeruli in ABIN1[D485N] mice compared with NTS alone. G: Model of our postulate concluded from the evidence in this report that genetic control of intrinsic glomerular ABIN1 function determines the susceptibility and extent of podocyte injury in glomerulonephritis via activation of neutrophil recruitment and release of granule products. Multivariate logistic regression analysis was used in $\mathbf{D}$ to compare dichotomous outcomes of actin remodeling and accounted for both ABIN1 genotype and exposure to granules. $n=3$ per condition (A); $n=3$ samples per condition with at least 30 cells analyzed per sample (C). The $t$-test and two-way analysis of variance determined significance in $\mathbf{A}, \mathbf{C}, \mathbf{E}$, and $\mathbf{F} .{ }^{*} P<0.05, * * P<0.01, * * * P<0.001$, and ${ }^{* * * * P}<0.0001$ versus controls. Scale bar $=$ $25 \mu \mathrm{m}$ (B and D). a.u., arbitrary unit; GBM, glomerular basement membrane; PMN, polymorphonuclear leukocyte. 
checkpoint to prevent immune and inflammatory disease. A role for ABIN1 as a physiological inhibitor of NF- $\mathrm{KB}$-mediated disease is indicated by development of autoimmunity and chronic kidney and other tissue inflammation in mice with loss of ABIN1 function or ABIN1 depletion. ${ }^{21,41}$ A mechanism for $\mathrm{ABIN} 1$ inhibition of NF- $\kappa \mathrm{B}$ is through its interaction with linear (M1-linked) or K63-linked polyubiquitin moieties on NF- $\mathrm{BB}$ mediator proteins NEMO, IRAK1, and RIP1, among others. ${ }^{20,42,43}$ These interactions prevent NEMO activation and phosphorylation and subsequent proteasome-mediated degradation of the NF- $\kappa B$ inhibitory I $\kappa$ B proteins, preventing nuclear translocation and gene transcription by the active NF- $\kappa \mathrm{B}$ subunits. ${ }^{44}$ The deubiquitinase and ubiquitin ligase protein A20 also regulates this process, and A20-deficient mice develop inflammatory phenotypes. ${ }^{45,46}$ ABIN1 and A20 directly interact, and A20-mediated deubiquitination and degradation of NEMO and subsequent NF- $\kappa$ B inhibition are ABIN1 dependent. ${ }^{17}$ A20 also interacts with IRAK1 and removes K63-linked polyubiquitin from the NF- $\kappa$ B mediators RIP1 and TRAF6. ${ }^{45}$ Other ubiquitinrelated negative NF- $\mathrm{KB}$ inhibitory mechanisms have also been identified. A deubiquitinase, OTULIN, specifically cleaves M1linked polyubiquitin moieties on NF-kB mediators, homozygous OTULIN mutation causes an autoinflammatory disorder in humans, and OTULIN deficiency results in multiorgan inflammation in mice. ${ }^{47,48}$ Two ubiquitin E3 ligases, PDLIM2 (LIM family protein) and MKRN2 (ring finger domain-containing protein), catalyze K48-linked polyubiquitination of the nuclear active p65 subunit of NF- $\kappa \mathrm{B}$, synergistically promoting p65 cytoplasm sequestration and proteasome-mediated degradation that subsequently inhibits NF- $\mathrm{KB}$ transcription activity. ${ }^{49-51}$

Reports support a role for intrinsic glomerular NF- $\kappa B$ signaling activation in exacerbated podocyte injury and inflammation in GN but have not defined a mechanism of activation. IHC-based studies have found enhanced glomerular expression of NF- $\kappa \mathrm{B}, \mathrm{NF}-\kappa \mathrm{B}$ regulatory proteins, and NF- $\kappa \mathrm{B}$ target proinflammatory cytokines in renal biopsy specimens from patients with systemic lupus erythematosus and GN compared with disease and healthy controls. ${ }^{14,15} \mathrm{~A}$ similar study reported enhanced glomerular cell NF- $\mathrm{KB}$ activation in kidney biopsy specimens from different cohorts of patients with proliferative GN, including membranoproliferative GN, IgA nephropathy, and mesangial proliferative IgM GN. ${ }^{52}$ Another group also found enhanced NF- $\mathrm{KB}$ activity in podocytes and other glomerular cells in biopsy specimens from patients with lupus nephritis and IgA nephropathy and patients with nonproliferative membranous nephropathy compared with healthy controls. ${ }^{53}$ More direct evidence of podocyte activity was indicated in a study that found that podocyte-specific NEMOdeficient mice have faster recovery from anti-GBMmediated glomerular injury. ${ }^{12}$ Glomerular expression of inflammatory chemokines (CCL2, CCL5, and CCL7) was also reduced in NEMO-deficient mice. Reduction of these chemokines after proinflammatory stimulation with IL- 1 and TNF- $\alpha$ was also observed in NEMO-deficient cultured podocytes. A consistent pattern in our in vivo and cell culture studies was that expression of the functionally deficient ABIN1 mutant resulted in enhanced NF- $\mathrm{BB}$ activation in unstimulated and stimulated conditions. Interpreted in conjunction with our identification of $A B I N 1$ gene variants in association with lupus nephritis, ${ }^{21}$ we propose ABIN1 dysfunction as a novel mechanism for the apparent enhanced glomerular NF- $\kappa$ B activity in human GN.

Our results of increased cytokine expression and secretion by cultured podocytes with ABIN1 dysfunction suggest that podocytes contribute to the glomerular proinflammatory microenvironment and that the microenvironment is regulated by ABIN1 function. Gene expression for two wellrecognized mediators of inflammation, TNF- $\alpha$ and IL- $1 \alpha$, were enhanced in TNF- $\alpha$-activated ABIN1[D472N] podocytes and glomeruli from NTS-treated ABIN1[D485N] mice. An important role for IL- $1 \alpha$ is implicated by a recent report that crossing ABIN1[D485N] mice with mice with inactive mutants of IRAK1 and IRAK4 prevented spontaneous development of kidney inflammation. ${ }^{54}$ Cellular IL- $1 \alpha$ activation of NF- $\kappa \mathrm{B}$ is IRAK1 dependent. ${ }^{55}$ In addition IL-1 receptor 1-deficient mice had reduced anti-GBM-induced podocyte injury compared with WT controls. ${ }^{56}$ Chemokines MCP-1, CXCL1, CXCL9, and CXCL10 that were elevated in ABIN1[D472N] podocytes have reported pathogenic roles in experimental and human GN. Injection of antibody against MCP1/CCL2 suppressed the progression of proliferative nephritis in MRL/lpr mice. ${ }^{57}$ Enhanced glomerular staining for CXCL1, CXCL9, and CXCL10 protein was observed in patients with proliferative GN. ${ }^{58,59}$ Elevated urinary levels of CXCL10/IP-10 and MCP-1 have been identified in association with disease activity in lupus nephritis patients. ${ }^{60}$

In conclusion, this report suggests an expanded pathogenic paradigm for GN shown in Figure 4G. After immunoglobulin deposition, podocytes and other intrinsic glomerular cells participate in local production of proinflammatory chemokines, cytokines, and other adhesion molecules. Those products lead to increased glomerular retention and activation of neutrophils, which undergo degranulation within glomerular capillaries. Those granule products induce actin cytoskeleton disorganization within podocytes, resulting in loss of the filtration barrier to protein. The degree of injury to podocytes is determined by regulators of NF- $\mathrm{KB}$ activation via two pathogenic mechanisms. The first mechanism is transcriptional regulation of podocyte production of the factors that recruit and activate neutrophils. The second is regulation of the actin cytoskeleton response on podocyte exposure to neutrophil granule products.

In closing, our study provides one link between genetic variants and intrinsic molecular events that determines the extent of immune complex glomerular injury. Our findings support a role for disrupted ABIN1-mediated NF- $\kappa$ B activity as one of those genetic variants.

\section{Acknowledgments}

The ABIN1[D485N] mouse model was a kind gift from Dr. Philip Cohen and Dr. Sambit Nanda (University of Dundee, 
Dundee, Scotland). Lentiviral vectors for ABIN1 WT and ABIN1[D472N] were produced by the Center for Molecular Medicine Genetic Technologies Core, directed by Dr. Michael Mendenhall (University of Kentucky, Lexington, KY).

\section{References}

1. Couser WG: Basic and translational concepts of immune-mediated glomerular diseases. J Am Soc Nephrol 2012, 23:381-399

2. Nangaku M, Couser WG: Mechanisms of immune-deposit formation and the mediation of immune renal injury. Clin Exp Nephrol 2005, 9:183-191

3. Thurman JM, Nester CM: All things complement. Clin J Am Soc Nephrol 2016, 11:1856-1866

4. Iwata Y, Furuichi K, Kaneko S, Wada T: The role of cytokine in the lupus nephritis. J Biomed Biotechnol 2011, 2011:1-7

5. Allam R, Anders H-J: The role of innate immunity in autoimmune tissue injury. Curr Opin Rheumatol 2008, 20:538-544

6. Hewins P, Morgan MD, Holden N, Neil D, Williams JM, Savage CO, Harper L: IL-18 is upregulated in the kidney and primes neutrophil responsiveness in ANCA-associated vasculitis. Kidney Int 2006, 69: 605-615

7. Kuravi SJ, McGettrick HM, Satchell SC, Saleem MA, Harper L, Williams JM, Rainger GE, Savage CO: Podocytes regulate neutrophil recruitment by glomerular endothelial cells via IL-6-mediated crosstalk. J Immunol 2014, 193:234-243

8. Lech M, Anders H-J: The pathogenesis of lupus nephritis. J Am Soc Nephrol 2013, 24:1357-1366

9. Davidson A: What is damaging the kidney in lupus nephritis? Nat Rev Rheumatol 2016, 12:143-153

10. Bruggeman LA, Drawz PE, Kahoud N, Lin K, Barisoni L, Nelson PJ: TNFR2 interposes the proliferative and NF- $\mathrm{KB}$-mediated inflammatory response by podocytes to TNF- $\alpha$. Lab Invest 2011, 91:413-425

11. Bao H, Ge Y, Peng A, Gong R: Fine-tuning of NFאB by glycogen synthase kinase $3 \beta$ directs the fate of glomerular podocytes upon injury. Kidney Int 2015, 87:1176-1190

12. Brähler S, Ising C, Hagmann H, Rasmus M, Hoehne M, Kurschat C, Kisner T, Goebel H, Shankland SJ, Addicks K, Thaiss F, Schermer B, Pasparakis M, Benzing T, Brinkkoetter PT: Intrinsic proinflammatory signaling in podocytes contributes to podocyte damage and prolonged proteinuria. Am J Physiol Renal Physiol 2012, 303:F1473-1485

13. Kalergis AM, Iruretagoyena MI, Barrientos MJ, Gonzalez PA, Herrada AA, Leiva ED, Gutierrez MA, Riedel CA, Bueno SM, Jacobelli SH: Modulation of nuclear factor-kappaB activity can influence the susceptibility to systemic lupus erythematosus. Immunology 2009, 128:e306-e314

14. Zheng L, Sinniah R, Hsu SI-H: In situ glomerular expression of activated NF-kappaB in human lupus nephritis and other non-proliferative proteinuric glomerulopathy. Virchows Arch 2006, 448:172-183

15. Zheng L, Sinniah R, Hsu SI: Pathogenic role of NF-kappaB activation in tubulointerstitial inflammatory lesions in human lupus nephritis. J Histochem Cytochem 2008, 56:517-529

16. Sakurai H, Hisada Y, Ueno M, Sugiura M, Kawashima K, Sugita T: Activation of transcription factor NF-kappa B in experimental glomerulonephritis in rats. Biochim Biophys Acta 1996, 1316:132-138

17. Mauro C, Pacifico F, Lavorgna A, Mellone S, Iannetti A, Acquaviva R, Formisano S, Vito P, Leonardi A: ABIN-1 binds to NEMO/IKKgamma and co-operates with A20 in inhibiting NF-kappaB. J Biol Chem 2006, 281:18482-18488

18. Vereecke L, Beyaert R, van Loo G: The ubiquitin-editing enzyme A20 (TNFAIP3) is a central regulator of immunopathology. Trends Immunol 2009, 30:383-391

19. Verstrepen L, Carpentier I, Verhelst K, Beyaert R: ABINs: a20 binding inhibitors of NF-kappa B and apoptosis signaling. Biochem Pharmacol 2009, 78:105-114
20. Nanda SK, Venigalla RK, Ordureau A, Patterson-Kane JC, Powell DW, Toth R, Arthur JS, Cohen P: Polyubiquitin binding to ABIN1 is required to prevent autoimmunity. J Exp Med 2011, 208:1215-1228

21. Caster DJ, Korte EA, Nanda SK, McLeish KR, Oliver RK, G'sell RT, et al: ABIN1 dysfunction as a genetic basis for lupus nephritis. J Am Soc Nephrol 2013, 24:1743-1754

22. Chugh S, Yuan H, Topham PS, Haydar SA, Mittal V, Taylor GA, Kalluri R, Salant DJ, Aminopeptidase A: A nephritogenic target antigen of nephrotoxic serum. Kidney Int 2001, 59:601-613

23. McLeish KR, Uriarte SM, Tandon S, Creed TM, Le J, Ward RA: Exocytosis of neutrophil granule subsets and activation of prolyl isomerase 1 are required for respiratory burst priming. J Innate Immun 2013, 5:277-289

24. Powell DW, Bertram CC, Cummins TD, Barati MT, Zheng S, Epstein PN, Klein JB: Renal tubulointerstitial fibrosis in OVE26 type 1 diabetic mice. Nephron Exp Nephrol 2009, 111:e11-e19

25. Barati MT, Gould JC, Salyer SA, Isaacs S, Wilkey DW, Merchant ML: Influence of acute high glucose on protein abundance changes in murine glomerular mesangial cells. J Diabetes Res 2016, 2016:3537863

26. Boudaoud A, Burian A, Borowska-Wykręt D, Uyttewaal M, Wrzalik R, Kwiatkowska D, Hamant O: FibrilTool, an ImageJ plug-in to quantify fibrillar structures in raw microscopy images. Nat Protoc 2014, 9:457-463

27. Saleem MA, O'Hare MJ, Reiser J, Coward RJ, Inward CD, Farren T, Xing CY, Ni L, Mathieson PW, Mundel P: A conditionally immortalized human podocyte cell line demonstrating nephrin and podocin expression. J Am Soc Nephrol 2002, 13:630-638

28. Fu Y, Du Y, Mohan C: Experimental anti-GBM disease as a tool for studying spontaneous lupus nephritis. Clin Immunol 2007, 124:109-118

29. Odobasic D, Ghali JR, O'Sullivan KM, Holdsworth SR, Kitching AR: Glomerulonephritis induced by heterologous anti-GBM globulin as a planted foreign antigen. Curr Protoc Immunol 2014, 106. 15.26.1-20

30. Klebanoff SJ: Myeloperoxidase: friend and foe. J Leukoc Biol 2005, 77:598-625

31. Bollée G, Flamant M, Schordan S, Fligny C, Rumpel E, Milon M, Schordan E, Sabaa N, Vandermeersch S, Galaup A, Rodenas A, Casal I, Sunnarborg SW, Salant DJ, Kopp JB, Threadgill DW, Quaggin SE, Dussaule J-C, Germain S, Mesnard L, Endlich K, Boucheix C, Belenfant X, Callard P, Endlich N, Tharaux P-L: Epidermal growth factor receptor promotes glomerular injury and renal failure in rapidly progressive crescentic glomerulonephritis. Nat Med 2011, 17:1242-1250

32. Endlich N, Kress KR, Reiser J, Uttenweiler D, Kriz W, Mundel P, Endlich K: Podocytes respond to mechanical stress in vitro. J Am Soc Nephrol 2001, 12:413-422

33. Santamaria B, Marquez E, Lay A, Carew RM, GonzálezRodríguez Á, Welsh GI, Ni L, Hale LJ, Ortiz A, Saleem MA, Brazil DP, Coward RJ, Valverde ÁM: IRS2 and PTEN are key molecules in controlling insulin sensitivity in podocytes. Biochim Biophys Acta 2015, 1853:3224-3234

34. Morigi M, Buelli S, Angioletti S, Zanchi C, Longaretti L, Zoja C, Galbusera M, Gastoldi S, Mundel P, Remuzzi G, Benigni A: In response to protein load podocytes reorganize cytoskeleton and modulate endothelin-1 gene: implication for permselective dysfunction of chronic nephropathies. Am J Pathol 2005, 166:1309-1320

35. Morigi M, Buelli S, Zanchi C, Longaretti L, Macconi D, Benigni A Moioli D, Remuzzi G, Zoja C: Shigatoxin-induced endothelin-1 expression in cultured podocytes autocrinally mediates actin remodeling. Am J Pathol 2006, 169:1965-1975

36. Uriarte SM, Rane MJ, Luerman GC, Barati MT, Ward RA, Nauseef WM, McLeish KR: Granule exocytosis contributes to priming and activation of the human neutrophil respiratory burst. J Immunol 2011, 187:391-400

37. Bai J, Tang L, Lomas-Neira J, Chen Y, McLeish KR, Uriarte SM, Chung C-S, Ayala A: TAT-SNAP-23 treatment inhibits the priming of neutrophil functions contributing to shock and/or sepsis-induced extra-pulmonary acute lung injury. Innate Immun 2015, 21:42-54 
38. Uriarte SM, Rane MJ, Merchant ML, Jin S, Lentsch AB, Ward RA, McLeish KR: Inhibition of neutrophil exocytosis ameliorates acute lung injury in rats. Shock Augusta Ga 2013, 39:286-292

39. G'Sell RT, Gaffney PM, Powell DW: A20-binding inhibitor of NF$\kappa \mathrm{B}$ activation 1 is a physiologic inhibitor of NF- $\kappa \mathrm{B}$ : a molecular switch for inflammation and autoimmunity. Arthritis Rheumatol 2015, 67:2292-2302

40. Adrianto I, Wen F, Templeton A, Wiley G, King JB, Lessard CJ, et al: Association between a functional variant downstream of TNFAIP3 and systemic lupus erythematosus. Nat Genet 2011, 43:253-258

41. Zhou J, Wu R, High AA, Slaughter CA, Finkelstein D, Rehg JE,

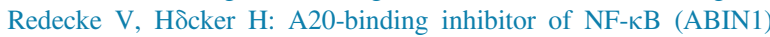
controls Toll-like receptor-mediated CCAAT/enhancer-binding protein $\beta$ activation and protects from inflammatory disease. Proc Natl Acad Sci U S A 2011, 108:E998-E1006

42. Wagner S, Carpentier I, Rogov V, Kreike M, Ikeda F, Löhr F, Wu CJ, Ashwell JD, Dötsch V, Dikic I, Beyaert R: Ubiquitin binding mediates the NF-kappaB inhibitory potential of ABIN proteins. Oncogene 2008, 27:3739-3745

43. Oshima S, Turer EE, Callahan JA, Chai S, Advincula R, Barrera J, Shifrin N, Lee B, Yen B, Woo T, Malynn BA, Ma A: ABIN-1 is a ubiquitin sensor that restricts cell death and sustains embryonic development. Nature 2008, 457:906-909

44. Heyninck K, Kreike MM, Beyaert R: Structure-function analysis of the A20-binding inhibitor of NF-kappa B activation, ABIN-1. FEBS Lett 2003, 536:135-140

45. Heyninck K, De Valck D, Vanden Berghe W, Van Criekinge W, Contreras R, Fiers W, Haegeman G, Beyaert R: The zinc finger protein A20 inhibits TNF-induced NF-kappaB-dependent gene expression by interfering with an RIP- or TRAF2-mediated transactivation signal and directly binds to a novel NF-kappaB-inhibiting protein ABIN. J Cell Biol 1999, 145:1471-1482

46. Matmati M, Jacques P, Maelfait J, Verheugen E, Kool M, Sze M, Geboes L, Louagie E, Guire CM, Vereecke L, Chu Y, Boon L, Staelens S, Matthys P, Lambrecht BN, Schmidt-Supprian M, Pasparakis M, Elewaut D, Beyaert R, van Loo G: A20 (TNFAIP3) deficiency in myeloid cells triggers erosive polyarthritis resembling rheumatoid arthritis. Nat Genet 2011, 43:908-912

47. Schaeffer V, Akutsu M, Olma MH, Gomes LC, Kawasaki M, Dikic I: Binding of OTULIN to the PUB domain of HOIP controls NF- $\kappa B$ signaling. Mol Cell 2014, 54:349-361

48. Damgaard RB, Walker JA, Marco-Casanova P, Morgan NV, Titheradge HL, Elliott PR, McHale D, Maher ER, McKenzie AN, Komander D: The deubiquitinase OTULIN is an essential negative regulator of inflammation and autoimmunity. Cell 2016, 166: $1215-1230 . e 20$

49. Tanaka T, Grusby MJ, Kaisho T: PDLIM2-mediated termination of transcription factor NF-kappaB activation by intranuclear sequestration and degradation of the p65 subunit. Nat Immunol 2007, 8:584-591

50. Ono R, Kaisho T, Tanaka T: PDLIM1 inhibits NF-kB-mediated inflammatory signaling by sequestering the $\mathrm{p} 65$ subunit of NF- $\mathrm{KB}$ in the cytoplasm. Sci Rep 2015, 5:18327

51. Shin $C$, Ito $Y$, Ichikawa $S$, Tokunaga $M$, Sakata-Sogawa $K$, Tanaka $T$ : MKRN2 is a novel ubiquitin E3 ligase for the $\mathrm{p} 65$ subunit of NF- $\mathrm{KB}$ and negatively regulates inflammatory responses. Sci Rep 2017, 7:46097

52. Danilewicz M, Wagrowska-Danilewicz M: The immunoexpression of glomerular NF- $\mathrm{BB}$ in proteinuric patients with proliferative and nonproliferative glomerulopathies. Pol J Pathol 2013, 64:78-83

53. Zhang H, Mao X, Sun Y, Hu R, Luo W, Zhao Z, Chen Q, Zhang Z: NF- $\kappa \mathrm{B}$ upregulates ubiquitin $\mathrm{C}$-terminal hydrolase 1 in diseased podocytes in glomerulonephritis. Mol Med Rep 2015, 12:2893-2901

54. Nanda SK, Lopez-Pelaez M, Arthur JSC, Marchesi F, Cohen P: Suppression of IRAK1 or IRAK4 catalytic activity, but not type 1 IFN signaling, prevents lupus nephritis in mice expressing a ubiquitin binding-defective mutant of ABIN1. J Immunol 2016, 197:4266-4273

55. Hartupee J, Li X, Hamilton T: Interleukin 1alpha-induced NFkappaB activation and chemokine mRNA stabilization diverge at IRAK1. J Biol Chem 2008, 283:15689-15693

56. Lichtnekert J, Kulkarni OP, Mulay SR, Rupanagudi KV, Ryu M, Allam R, Vielhauer V, Muruve D, Lindenmeyer MT, Cohen CD, Anders H-J: Anti-GBM glomerulonephritis involves IL-1 but is independent of NLRP3/ASC inflammasome-mediated activation of caspase-1. PLoS One 2011, 6:e26778

57. Devarapu SK, Kumar Vr S, Rupanagudi KV, Kulkarni OP, Eulberg D, Klussmann S, Anders H-J: Dual blockade of the proinflammatory chemokine CCL2 and the homeostatic chemokine CXCL12 is as effective as high dose cyclophosphamide in murine proliferative lupus nephritis. Clin Immunol 2016, 169:139-147

58. Romagnani P, Lazzeri E, Lasagni L, Mavilia C, Beltrame C, Francalanci M, Rotondi M, Annunziato F, Maurenzig L, Cosmi L, Galli G, Salvadori M, Maggi E, Serio M: IP-10 and Mig production by glomerular cells in human proliferative glomerulonephritis and regulation by nitric oxide. J Am Soc Nephrol 2002, 13:53-64

59. Kowalewska J, Okoń K, Szynaka B, Naumnik B: Expression of macrophage markers in cryoglobulinemic glomerulonephritis - a possible role of CXCL9. Adv Med Sci 2013, 58:394-400

60. Abujam B, Cheekatla S, Aggarwal A: Urinary CXCL-10/IP-10 and MCP-1 as markers to assess activity of lupus nephritis. Lupus 2013, 22:614-623 